\title{
Initial steps to measurement and improvement of family- centered communication during the pediatric patient journey of bone marrow transplantation
}
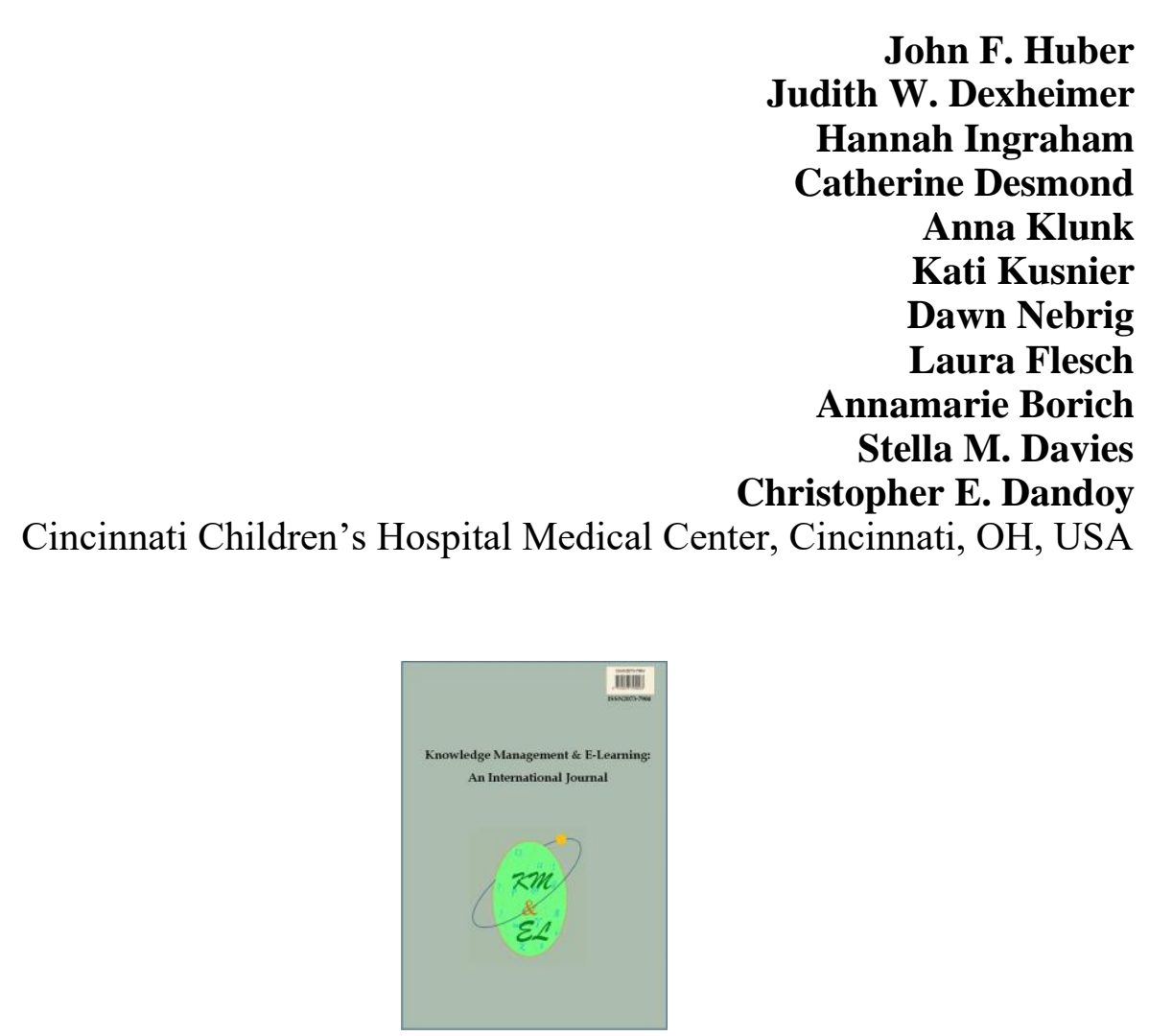

Knowledge Management \& E-Learning: An International Journal (KM\&EL) ISSN 2073-7904

Recommended citation:

Huber, J. F., Dexheimer, J. W., Ingraham, H., Desmond, C., Klunk, A., Kusnier, K., Nebrig, D., Flesch, L., Borich, A., Davies, S. M., \& Dandoy, C. E. (2020). Initial steps to measurement and improvement of familycentered communication during the pediatric patient journey of bone marrow transplantation. Knowledge Management \& E-Learning, 12(4), 488-504. https://doi.org/10.34105/j.kmel.2020.12.027 


\section{Initial steps to measurement and improvement of family- centered communication during the pediatric patient journey of bone marrow transplantation}

\section{John F. Huber* (1)}

Division of Bone Marrow Transplantation \& Immune Deficiency Cincinnati Children's Hospital Medical Center, Cincinnati, OH, USA

E-mail: John.Huber@cchmc.org

\section{Judith W. Dexheimer (10)}

Division of Emergency Medicine

Cincinnati Children's Hospital Medical Center, Cincinnati, OH, USA

E-mail: Judith.Dexheimer@cchmc.org

\section{Hannah Ingraham}

Office for Clinical and Translational Research

Cincinnati Children's Hospital Medical Center, Cincinnati, OH, USA

E-mail: Hannah.Ingraham@cchmc.org

\section{Catherine Desmond}

Division of Bone Marrow Transplantation \& Immune Deficiency Cincinnati Children's Hospital Medical Center, Cincinnati, OH, USA E-mail: Catherine.Desmond@cchmc.org

\section{Anna Klunk \\ Division of Bone Marrow Transplantation \& Immune Deficiency Cincinnati Children's Hospital Medical Center, Cincinnati, OH, USA E-mail: Anna.Klunk@cchmc.org}

\section{Kati Kusnier (10)}

Division of Bone Marrow Transplantation \& Immune Deficiency Cincinnati Children's Hospital Medical Center, Cincinnati, OH, USA E-mail: Katilyn.Kusnier@cchmc.org

\section{Dawn Nebrig [i]}

Family Relations

Cincinnati Children's Hospital Medical Center, Cincinnati, OH, USA

E-mail: Dawn.Nebrig@cchmc.org 


\title{
Laura Flesch
}

Division of Bone Marrow Transplantation \& Immune Deficiency Cincinnati Children's Hospital Medical Center, Cincinnati, OH, USA E-mail: Laura.Flesch@cchmc.org

\author{
Annamarie Borich \\ Division of Bone Marrow Transplantation \& Immune Deficiency \\ Cincinnati Children's Hospital Medical Center, Cincinnati, OH, USA \\ E-mail: Annamarie.Borich@cchmc.org
}

\section{Stella M. Davies}

Division of Bone Marrow Transplantation \& Immune Deficiency Cincinnati Children's Hospital Medical Center, Cincinnati, OH, USA E-mail: Stella.Davies@cchmc.org

\section{Christopher E. Dandoy}

Division of Bone Marrow Transplantation \& Immune Deficiency Cincinnati Children's Hospital Medical Center, Cincinnati, OH, USA E-mail: Christopher.Dandoy@cchmc.org

*Corresponding author

\begin{abstract}
Often, pediatric patients' caregivers feel like they are not being heard or consulted by the healthcare system they have entrusted for their loved ones' care. These difficulties are well known to the healthcare system, and significant research has been conducted to understand how to provide what's come to be known as patient- and family-centered care (PFCC). PFCC is grounded in mutually beneficial partnerships among health care providers, patients, and families. In 2019 we started a quality improvement initiative, partnering with families to increase our family-centeredness, initially focusing on communication. We report our quality improvement initiative's initial steps to understand communication between patients and caregivers in the inpatient setting. We report variables identified as barriers to PFCC, and our initial interventions, including small tests of change, to implement and improve PFCC in the inpatient setting. We hope that our experience will inspire others to undertake similar initiatives at their institutions.
\end{abstract}

Keywords: Quality improvement; Patient-centered care; Communication; Patient participation; Inpatients

Biographical notes: John Huber is a lead analyst in the Division of Bone Marrow Transplantation \& Immune Deficiency at Cincinnati Children's Hospital Medical Center. He is also a second-year biomedical informatics Ph.D. student at the University of Cincinnati.

Dr. Judith Dexheimer is an associate professor in the Department of Pediatrics, University of Cincinnati and the Division of Biomedical Informatics, Cincinnati Children's Hospital Medical Center. Dr. Dexheimer's current appointment is in the Division of Emergency Medicine, Cincinnati Children's 
Hospital Medical Center, where she focuses on the applications of AI and machine learning in the field of clinical informatics.

Hannah Ingraham is a clinical research nurse in the Office for Clinical and Translational Research, Cincinnati Children's Hospital Medical Center.

Catherine Desmond is a student in the Division of Bone Marrow Transplantation and Immune Deficiency, Cincinnati Children's Hospital Medical Center.

Anna Klunk is a student in the Division of Bone Marrow Transplantation and Immune Deficiency, Cincinnati Children's Hospital Medical Center.

Kati Kusnier is a nurse practitioner in the Division of Bone Marrow Transplantation and Immune Deficiency, Cincinnati Children's Hospital Medical Center.

Dawn Nebrig is the director of Family Relations at the Cincinnati Children's Hospital Medical Center.

Dr. Laura Flesch is the clinical director in the Division of Bone Marrow Transplantation and Immune Deficiency, Cincinnati Children's Hospital Medical Center.

Annamarie Borich is a registered nurse II in the Division of Bone Marrow Transplantation and Immune Deficiency, Cincinnati Children's Hospital Medical Center.

Dr. Stella Davies is a professor in the Department of Pediatrics, University of Cincinnati and the director of the Division of Bone Marrow Transplantation and Immune Deficiency, Cincinnati Children's Hospital Medical Center. Dr. Davies is also the co-director of the Cancer and Blood Diseases Institute, Cincinnati Children's Hospital Medical Center.

Dr. Christopher Dandoy is an assistant professor in the Department of Pediatrics, University of Cincinnati and an attending physician in the Division of Bone Marrow Transplantation and Immune Deficiency, Cincinnati Children's Hospital Medical Center. Dr. Dandoy is also the leader of quality improvement for the Division of Bone Marrow Transplantation and Immune Deficiency, Cincinnati Children's Hospital Medical Center.

\section{Introduction}

One can imagine the frustration a parent (or caregiver) may feel in seeing their child's discomfort but not being able to convince the healthcare team to deviate from the current pain management plan. The helplessness arising from knowing something isn't right with their child but unable to persuade a healthcare provider that what they see is genuinely abnormal; frustration and anger that the healthcare team isn't listening. "Why aren't they listening?" is an all too common refrain in any hospital, and these experiences may bring helplessness, anger, and frustration (Sobo et al., 2006). Caregivers frequently feel like they are not being heard or consulted by the healthcare system they have entrusted for their loved ones care (Rosenberg et al., 2016). Parent-provider miscommunication and parental uncertainty is common in pediatric hospitalized patients and can occur in up to 
$41 \%$ of hospitalizations (Khan et al., 2017). Not every failure to communicate is emotionally charged, but even simple misunderstandings can be impactful. Misunderstanding about medication administration schedules could result in medication errors (Aspen et al., 2007), miscommunications about procedure times can lead to improper preparation and lead to operating room delays (Levine \& Dunn, 2015), and ambiguity about care responsibilities can result in something as simple as inconsistent personal care practices, which may increase infection risk (Best et al., 2016).

The National Academy of Medicine and the National Cancer Institute call for improved patient-provider communication in the context of severe illnesses, citing effects of good communication on quality of care and quality of life, and an ethical mandate that patients be offered participation in informed decisions regarding their care (Epstein \& Street, 2007; IOM, 2009; National Priorities Partnership, 2008). In severe illness, inadequate communication about prognosis and treatment choices is common (DesHarnais et al., 2007; Epstein \& Street, 2007; Weeks et al, 2012). Patient and familycentered communication (PFCC) is an essential component of high-quality medical care. By providing trustworthy information that is attentive, responsive, and tailored to a patient's needs, clinicians can improve patient and family satisfaction, quality of life, and other essential health outcomes (Epstein, Franks, Fiscella, et al., 2005; Epstein, Franks, Shields, et al., 2005). The core concepts of PFCC include: 1) eliciting and understanding patient perspectives, 2) understanding the patient and family within his or her unique psychosocial and cultural contexts, and (3) reaching a shared understanding of patient problems and the treatments that are concordant with patient values (Arora et al, 2009; Epstein, Franks, Fiscella, et al., 2005; King \& Hoppe, 2013).

During prolonged hospitalization, patients and caregivers experience countless conversations between their primary physician, the inpatient physician team, nursing staff, ancillary services, and consulting services. Frequently, it is left to pediatric patients' caregivers to make sense of all of these conversations, and they may or may not be aware of communication within and across teams (Epstein et al., 2017; Epstein \& Street, 2007; Hashem et al., 2016; Makoul \& Clayman, 2006; Treiman et al., 2018). Optimal PFCC attempts to coordinate and convey these conversations and break down barriers to understanding. These critical conversations can also occur at emotional times, such as when a patient receives an abnormal test result, new life-threatening complications arise, or when the child transitions to end of life care (Epstein et al., 2017).

In the inpatient setting, measurement and monitoring of PFCC are essential to improving patient-centered care. Safety and satisfaction are foundationally interrelated with good communication that as care complexity increases, both become vital to ensuring good outcomes. While excellent patient-provider communication is desirable in all aspects of healthcare, it is essential when the patient is undergoing a bone marrow transplant (BMT). Each year, thousands of patients undergo BMT for malignancy, bone marrow failure, and hereditary conditions (Majhail et al., 2015). BMT is a procedure that replaces defective, damaged, or malignant cells with healthy stem cells (autologous or allogeneic) to normalize the production of blood cells or to allow an otherwise lethal dose of chemotherapy to be used (Gratwohl et al., 2010; Passweg et al., 2014). BMT is associated with extended hospitalization stays and prolonged recovery time accompanied by profound immunosuppression, which can be associated with significant complications. During BMT in children, the pediatric patient is hospitalized in isolation for weeks to months and often will have one and sometimes two sets of primary caregivers with them 24 hours a day throughout the treatment. Opportunity for rapid deterioration is everpresent, so patients are frequently monitored for changes in their condition (Badia et al., 2019; Dandoy et al., 2014). 
In 2019 we started a quality improvement initiative, partnering with families to increase family-centeredness, initially focusing on communication, with our first aim being to increase participation in family-centered rounds. Daily rounds are the time when the healthcare delivery team (often multidisciplinary) meets with the caregiver and patent to discuss the patient's condition and coordinate care. Rounds are an ideal opportunity to build a productive parent partnership where time is set aside for the patient or caregiver to raise any concerns they have about what has happened or what will happen. There can be many benefits to this approach. Family-centered medicine recognizes the family as an expert in key aspects of the child's health. The parent is often the person who has spent and does spend the most time with the child and can recognize changes in the child's condition sooner than anyone else on the care team. The parent also has extensive knowledge of the child's health history and can contribute valuable insights regarding the results of previous procedures and medications. The promotion of daily family-centered rounds for all inpatient units is one of the key processes for implementing familycentered care at our institution (Muething et al., 2007).

This article documents our process to date: what we've done, what we've learned so far, and where we're going next.

\section{Methods}

\subsection{Setting and context}

Cincinnati Children's Hospital Medical Center is a large, urban pediatric medical center, and the BMT service performs approximately 110 transplants per year. The BMT unit contains 36 rooms that accommodate a patient and caregiver. BMT patients require frequent nursing assessments, physical and emotional support, interventions for laboratory monitoring, medication administration, transfusions, nutrition support, and cleaning services. The clinical providers caring for patients include 14 attending physicians, 15 fellows, seven nurse practitioners, and six hospitalists. The hospitalists provide 24-hour coverage for all patients. The BMT unit employs approximately 130 bedside registered nurses (RN) and 30 patient care assistants (PCA). Family members take an active role in the care of patients in the BMT unit as participants in the Family Advisory Council and through daily patient/family-centered rounds (Muething et al., 2007).

The present initiative fell within the Cincinnati Children's Hospital Medical Center institutional review board's guidance for quality improvement projects that did not constitute human subjects research.

\subsection{Development of key drivers}

In 2019, we created a team consisting of nurses, social workers, physicians, and parents of hospitalized patients to be part of the quality improvement initiative. The team reviewed barriers to communication between patients and caregivers and the healthcare delivery team. Failure modes and potential interventions were recognized, and key drivers identified. The drivers included both the caregivers and staff understanding the potential benefits and barriers of effective communication, awareness, and acknowledgment of caregiver communication preferences, practical communication skills such as how to advocate for your child and active listening for the staff, making sure opportunities for communication were known and functioning appropriately, and finally 
developing a system for recovery actions that can be initiated when issues around communication occur (Fig. 1). Increasing rounds participation was the first intervention selected, and we began this work by establishing baseline data through the collection of 4 measures.

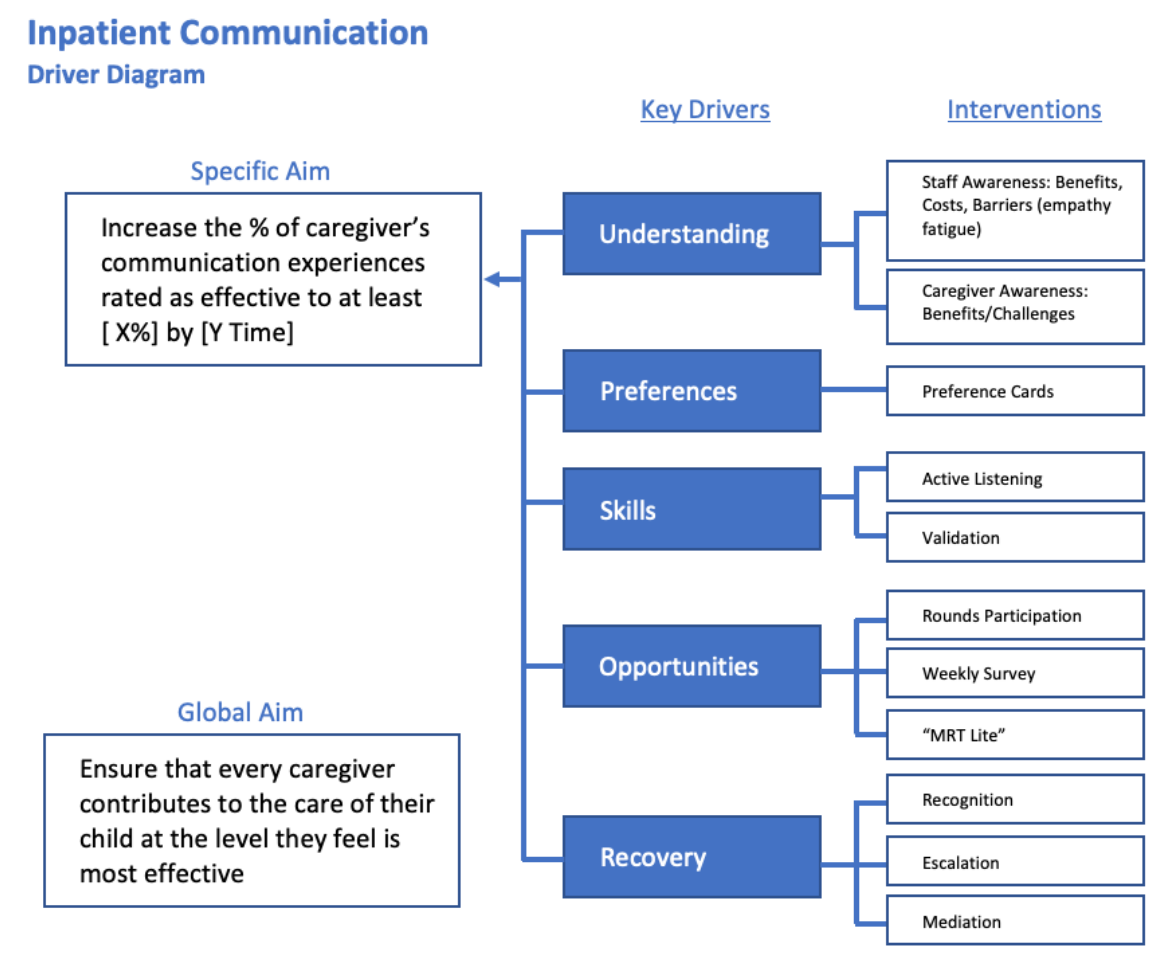

Fig. 1. Improving communication key driver diagram

\subsection{Outcome measures}

\subsubsection{Measure 1 - Family participation in daily rounds (percentage)}

We assessed current participation in rounds by family caregivers through an existing data capture process. Each day, a member of the rounds team records the patient census and the number of present families. Our measure of family participation is the ratio of the family participating divided by the patient census, shown as a percentage. Our goal is to increase family participation. The daily frequency of data collection will allow us to see small changes in participation as interventions are delivered.

\subsubsection{Measure 2 - Individual participation frequency}

Assessed through a survey, parents respond with one of five participation levels, from always to never. This measure will allow us to see changes in individual behavior that might be hidden in the aggregate daily participation percentage. 


\subsubsection{Measure 3 - Endorsed barrier}

Parents can endorse barriers to rounds participation through the interactive survey. We will expect an endorsement of barriers to decrease as interventions are performed.

\subsubsection{Measure 4-Participation benefit frequency}

Assess through a survey; parents can indicate how often participation in rounds delivers benefits across five different domains. Frequency values are provided on a five-point scale ranging from Always to Never.

\subsection{Assessment of measures}

Our primary approach for assessing the value of our measures is to compare the results of our efforts to the content of discussions with focus groups of caregivers selected from the same population. This approach provides insights into the correctness of our interpretations of the data and gaps in our measures. Feedback from these focus groups will allow adjustments to the measures as our understanding evolves.

\section{Results}

\subsection{Participation in rounds}

Data collected during rounds showed that the percentage of families attending rounds ranged between $42 \%$ and $66 \%$, providing significant room for improvement for an activity we considered critical to effective communication between a parent and the rest of their child's care team.

\subsection{Survey measurement of PFCC}

We administered an investigator-initiated survey to better understand how our team was delivering care in accordance with the PFCC principles (Fig. 2). This survey, designed to be quickly completed by parents, captured how often they participated in rounds, what gets in the way of them participating, and how often participation result in benefits across five core areas. We also provide a blank space for the parent to tell us how to improve rounds and communication. We collected 20 surveys from caregivers of children undergoing transplant $(\mathrm{n}=20)$.

Results for how often parents participated in rounds reflected what we had seen in our aggregate participation measure. $40 \%(\mathrm{n}=8)$ of the parents reported that they always attended rounds, 20\% $(\mathrm{n}=4)$ reported attending 5-6 days a week, and 20\% $(\mathrm{n}=4)$ reported attending 3-4 days a week. Attending 1-2 times a week was our lowest reported at $5 \%(\mathrm{n}=1)$. And finally, $15 \%(\mathrm{n}=3)$ caregivers reported never attending rounds. (Table 1). 


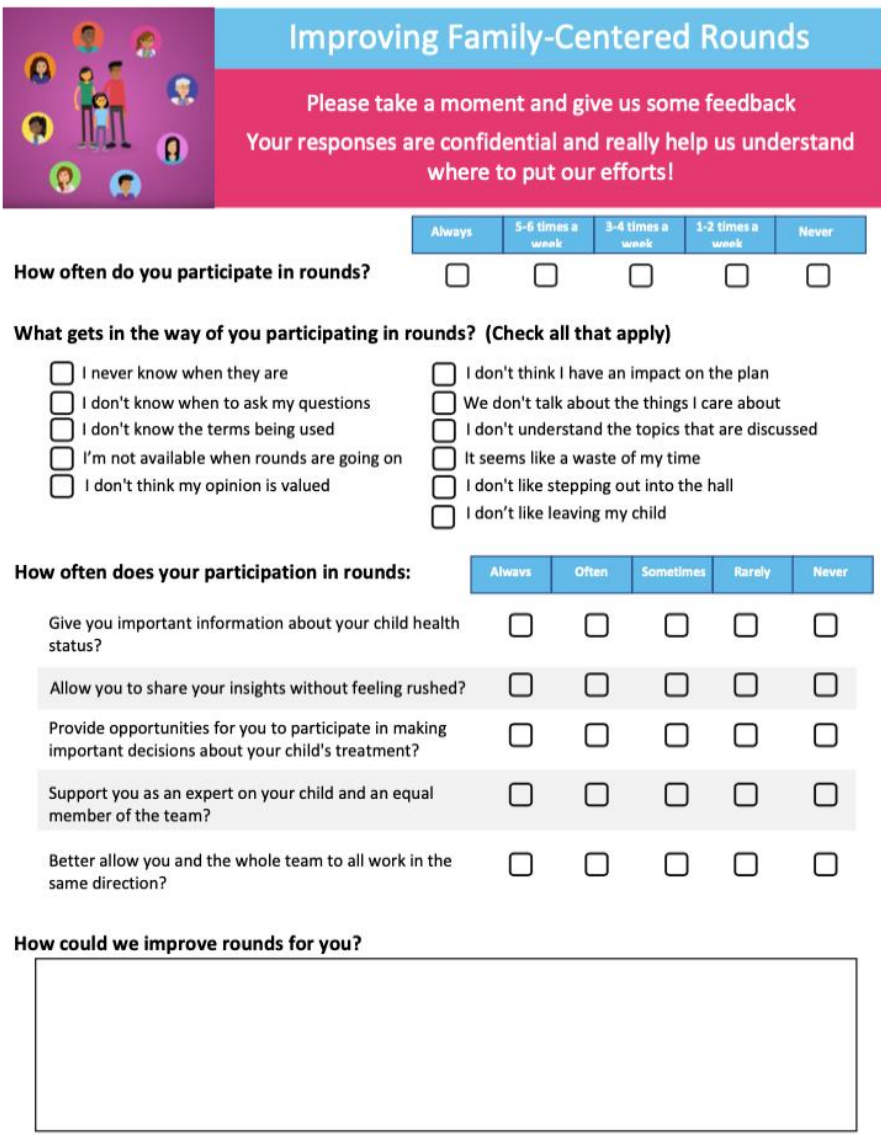

Fig. 2. Improve family-centered rounds survey

Table 1

Summary of caregiver frequency of attending rounds

\begin{tabular}{ccc}
\hline Response & Percentage & $\mathrm{N}$ \\
\hline Always & $40 \%$ & 8 \\
5-6 Days & $20 \%$ & 4 \\
2-4 Days & $20 \%$ & 4 \\
1-2 Days & $5 \%$ & 5 \\
Never & $15 \%$ & 3 \\
\hline
\end{tabular}

$70 \%$ of the caregivers endorsed at least one of the eleven barriers provided. Six of the eleven barriers have at least one endorsement with "I'm not available when rounds are going on" and "I never know when they are" receiving the most endorsements, six and 
five, respectively. "I don't like leaving my child," was next most endorsed with two. The remaining endorsed items were selected only once. (Table 2).

Table 2

Summary of barrier endorsements

\begin{tabular}{lc}
\hline \multicolumn{1}{c}{ Barrier } & Endorsement Count $(\mathrm{N})$ \\
\hline I'm not available when rounds are going on & 6 \\
I never know when they are & 5 \\
I don't like leaving my child & 2 \\
I don't think I have an impact on the plan & 1 \\
I don't understand the topics that are discussed & 1 \\
I don't like stepping out into the hall & 1 \\
I don't know when to ask my questions & 0 \\
I don't know the terms being used & 0 \\
I don't think my opinion is valued & 0 \\
We don't talk about the things I care about & 0 \\
It seems like a waste of time & 0 \\
\hline
\end{tabular}

Note. Caregivers were asked if any of the listed barriers gets in the way of them attending rounds

Responses to how often participation in rounds provided five key benefits (information delivery, sharing insights without being rushed, involvement in important decisions, being recognized as an expert and essential member of the team, and allowing for more alignment within the team) were highly positive. Parents were given response choices ranging from Always to Never on a 5-point scale. Aside from one parent who responded "rarely (2)" across all questions, all other responses were Often (4), or Always (5). This resulted in very similar means in the range of 4.6 to 4.8 . All between often and always. (Table 3).

Table 3

Summary of rounds benefit frequency

\begin{tabular}{lcc}
\hline Question: How often does your participation in rounds & Mean & StdDev \\
\hline $\begin{array}{l}\text { Give you important information about your child } \\
\text { health status? }\end{array}$ & 4.75 & 0.70 \\
$\begin{array}{l}\text { Allow you to share your insights without feeling } \\
\text { rushed? }\end{array}$ & 4.60 & 0.73 \\
$\begin{array}{l}\text { Provide opportunities for you to participate in making } \\
\text { important decisions about your child's treatment? }\end{array}$ & 4.60 & 0.80 \\
$\begin{array}{l}\text { Support you as an expert on your child and an equal } \\
\text { member of the team? }\end{array}$ & 4.65 & 0.79 \\
$\begin{array}{l}\text { Better allow you and the whole team to all work in the } \\
\text { same direction? }\end{array}$ & 4.80 & 0.68 \\
\hline
\end{tabular}

Note. 5 -point scale with Always $=5$ and Never $=1$ 
Written responses to "how we could improve rounds for you" were provided in just over one-half of the surveys $(55 \%, \mathrm{n}=11)$. Common themes mirrored the most selected barriers of not knowing when rounds would be occurring and not wanting to leave their child. Three of the responses provided praise for the team on how rounds where performed. (Table 4).

Table 4

Summary of themes of improvement feedback with examples

\begin{tabular}{|c|c|}
\hline Theme & How could we improve rounds for you? \\
\hline Scheduling & $\begin{array}{l}\text { - Rounds would be easier to attend if the time frame was narrowed down a little. For } \\
\text { example instead of saying 9-11, and it occurring sometime between 9-11:30 a shorter } \\
\text { time frame would help. } \\
\text { - Have rounds at a specific time each day, so I know when they are to be able to attend. } \\
\text { There have been times when I've not been woke up for rounds when I have stated } \\
\text { several times to wake me and it is on the sign outside my child's room. } \\
\text { - I do not sleep in Hospital Room, so I drive in first thing in morning to be here for } \\
\text { Rounds. Many times I rush to get here by } 8 \mathrm{am} \& \text { rounds aren't until } 11 \text { am--just a } \\
\text { "window" would be nice (i.e. like between } 10-11 \mathrm{am} \text { ). } \\
\text { - "sometimes doesn't know when they are, sometimes asleep"; "Y'all have permission to } \\
\text { wake us up if we are asleep. :) Even when we aren't at rounds, someone always keeps us } \\
\text { updated which we appreciate." } \\
\text { - A } 10-15 \text { min heads up would be nice. That would give me time to brush hair and teeth. } \\
\text { Especially when we are the first ones to round. When our time is later in the morning } \\
\text { this obviously isn't as important. }\end{array}$ \\
\hline Can't leave child & $\begin{array}{l}\text { - On the days I don't go out into the hall, I miss certain information. Unless I'm thinking to } \\
\text { ask, I miss her counts or the daily plan. Sometimes there are meds being ordered for her } \\
\text { that I don't know about. Unless the rounds are moved inside the room, I would like a } \\
\text { complete recap of where my child is. } \\
\text { - Would always participate in rounds, but can't on the days when he is awake. He is in } \\
\text { contact. }\end{array}$ \\
\hline Praise & $\begin{array}{l}\text { - To me the team is doing a fantastic job and it is left for us parents to cooperate with the } \\
\text { care team. } \\
\text { - N/A I really like how rounds are done }\end{array}$ \\
\hline
\end{tabular}

\subsection{Focus group discussion with patients and families}

We invited parents and caregivers to join us in the parent lounge to discuss their communication experiences at the hospital. We prompted participation with a question we thought would resonate with them, "Are you being heard?" and appealed to a common desire to improve the situation for both themselves and others. Five parents (4 female, 1 male) of children undergoing BMT attended the meeting, which lasted approximately one hour.

In a technique recommended by the meeting facilitator who had extensive experience interviewing patients and families, we first asked the caregivers to focus on their positive communication experiences. The caregivers reported their care team attempted to make sure they understood what was happening. They spoke of how they'd 
often be asked by their nurses if they needed anything or if there was anything they could do for them. All also reported feeling like part of the care team. In the second half of the focus group, we asked the caregivers to focus on their negative communication experiences. Parents spoke of the annoyance of people coming into the room and not introducing themselves. Many spoke of being surprised by procedures occurring without their knowledge, especially at night, where the care plan is continued, and the parent may be sleeping. When asked to go deeper, one mother spoke about not being valued in a specific incident around her child's pain management. This mother was an RN herself, and she believed that the team had difficulty listening to her as an equal as she relayed her child's medical history. Parents spoke about being selective with their questions and feedback. Many were aware of the time constraints the doctors were under and would choose to say they understood something, even when they didn't thoroughly understand, but thought the doctor was spending too much time with them. Parents reported not wanting to take attention away from their child so they wouldn't bring up challenges that they or their family were having, even when asked if there was anything that they needed. And finally, many reported not wanting to ask repeatedly about a problem even if the time stated for resolution had elapsed by more than several days. The difficulty bringing up treatment-related complications previously discussed, which had not improved, was one of the most common sources of frustrations for the parents. The initial surveys and the focus group provided us with a baseline set of measurement values and a set of experience data useful for designing our first set of interventions. (Table 5).

Table 5

Summary of focus group feedback

\begin{tabular}{|c|c|}
\hline Theme & Reported Situation \\
\hline Improper Introduction & $\begin{array}{l}\text { - Providers entering the patient room and not introducing themselves } \\
\text { - Patients unaware of which medical service the healthcare provider was } \\
\text { from } \\
\text { - Providers referring to parents as "mom" or "dad" }\end{array}$ \\
\hline Difficulty in exchanging information & $\begin{array}{l}\text { - Being selected with their questions and feedback due to the time } \\
\text { constraints of the healthcare team } \\
\text { - Parents reported not wanting to take attention away from their child so } \\
\text { they wouldn't discuss challenges that they or their family were having, } \\
\text { even when asked repeatedly if there was anything they needed } \\
\text { - Caregiver opinions regarding management being overlooked }\end{array}$ \\
\hline $\begin{array}{l}\text { Poor communication regarding } \\
\text { decisions }\end{array}$ & $\begin{array}{l}\text { - Procedures occurring without the parent's knowledge when they were } \\
\text { away from the hospital }\end{array}$ \\
\hline Managing Uncertainty & $\begin{array}{l}\text { - Feelings of frustration that things were not happening when it was } \\
\text { stated they would. } \\
\text { - Feelings of not wanting to repeatedly ask about a problem even if the } \\
\text { time stated for resolution has elapsed by more than several days. }\end{array}$ \\
\hline $\begin{array}{l}\text { Speaking above or below the } \\
\text { caregiver's knowledge level }\end{array}$ & $\begin{array}{l}\text { - Providers using medical terminology that was difficult to understand } \\
\text { - One parent who was a medical provider herself stated that it was } \\
\text { difficult to get the team to discuss the child's medical history as an } \\
\text { equal }\end{array}$ \\
\hline
\end{tabular}




\section{Discussion}

We report our quality improvement initiative's initial steps to understand communication between patients and caregivers in the inpatient setting. We identified barriers to PFCC through group discussion and survey administration. The surveys identified gaps in coordination between the healthcare team and caregivers for the timing of rounds and a feeling that their voice may not be heard by the team. These data have helped us establish our next steps.

A working partnership must exist between caregivers and providers in the BMT setting. The discussion surrounding care plans and status changes must be communicated, and collaboration between the caregivers and the treatment team is vital to success. But such partnerships are not easy to foster in the modern healthcare environment (Kerr et al., 2003; Llenore \& Ogle, 1999; Sutcliffe et al., 2004). Communication can be difficult in a familiar environment, and an inpatient stay for BMT is anything but ordinary. Patients and caregivers experience information overload as they acclimate to hospital life and connections with those outside the hospital become harder to maintain (Kaziunas et al., 2016). Patients and their families are exposed to new schedules, new processes, unknown language, and new expectations during an already traumatic life event. Additionally, patients and their families are often sleep-deprived due to frequent interruptions and uncomfortable beds (Badia et al, 2019; Coleman et al., 2018). Caregivers report trying to absorb things as quickly as possible but usually not understanding a medical term or the significance of a laboratory result (Frosch et al., 2012). Additionally, parents report having concerns but not wanting to risk upsetting the team or being labeled a "problem parent," even worrying that disagreements with the treating team will impact their child's care (Frosch et al., 2012).

\subsection{Limitations}

Our focus group was conducted in March of 2020, and shortly after that, the COVID-19 pandemic halted our progress on interventions. To lower the risk of infection spread, we limited our interactions with patients and families on the unit and the staff that was caring for them. Despite not yet moving forward with interventions, we have gained a significantly deeper appreciation for the challenges ahead. An appreciation that will benefit us as we move forward. Building a system to support effective communication across a diverse population is a difficult task. A task made more difficult as measuring the effectiveness of the system is difficult as well. The first half of our focus group was, by design, entirely, even glowingly positive, while most of our participants had experienced significant lapses in communication.

Our survey responses on the frequency of benefits delivered during rounds were highly positive and the barriers identified were more associated with the logistics of rounds, not the experience of the rounds itself. It would be easy to take these results and conclude there isn't much room for improvement because everyone is satisfied. However, we must also note that both participation in rounds is still lower than we'd expect for such an important and positive activity, and our survey didn't capture any of the negative experiences parents shared during our focus group. Perhaps our survey sample didn't include parents with a negative experience to share, but that seemed unlikely.

Therefore, it is critical to understand that both positive and negative experiences can (and do) exist simultaneously and that it may be necessary to utilize different techniques to build a comprehensive understanding of the patient and caregiver 
experience. We've also come to better understand how the experience can change over time, indicating that evaluating circumstances at multiple timepoints is essential.

\subsection{Next steps}

Our work is not over; in fact, we're very much at the beginning of our efforts to improve communication with our patients and families. We will be testing the following interventions in the upcoming months. The first of these interventions will be a new room sign created to increase caregivers' awareness of the many potential benefits of rounds. It includes a description of daily rounds, who will attend, and the benefits of joining the team. (Fig. 3).

\section{Please Join Us for Daily Rounds!}
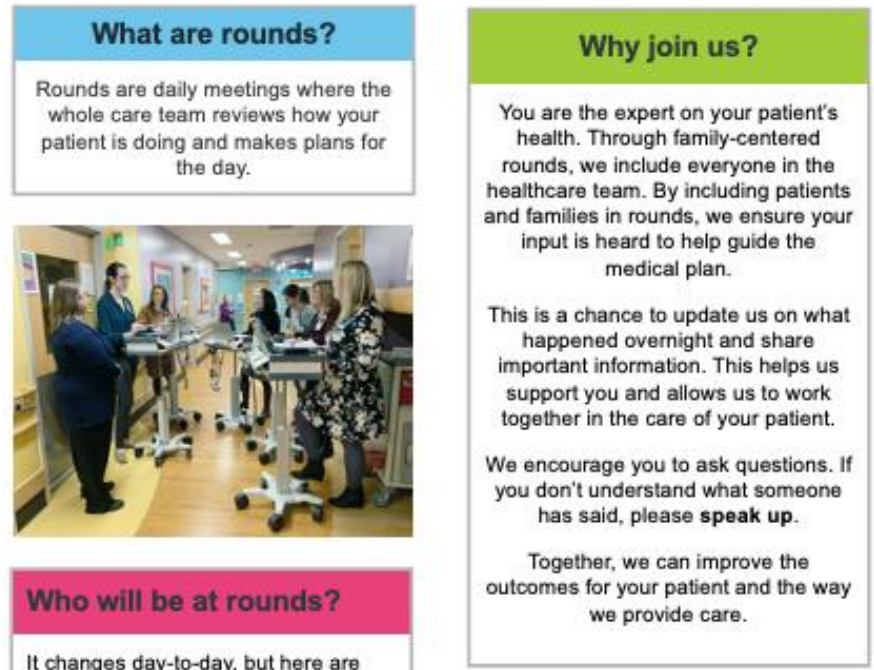

It changes day-to-day, but here ar some of the people on our team:

Doctors (BMT attendings, hospitalists) Pharmacist

Nurse Practioner

Bedside Nurse

Care Manager

Charge Nurse

Charge Nurse

Social Worke

Doctors Completing Medical Training
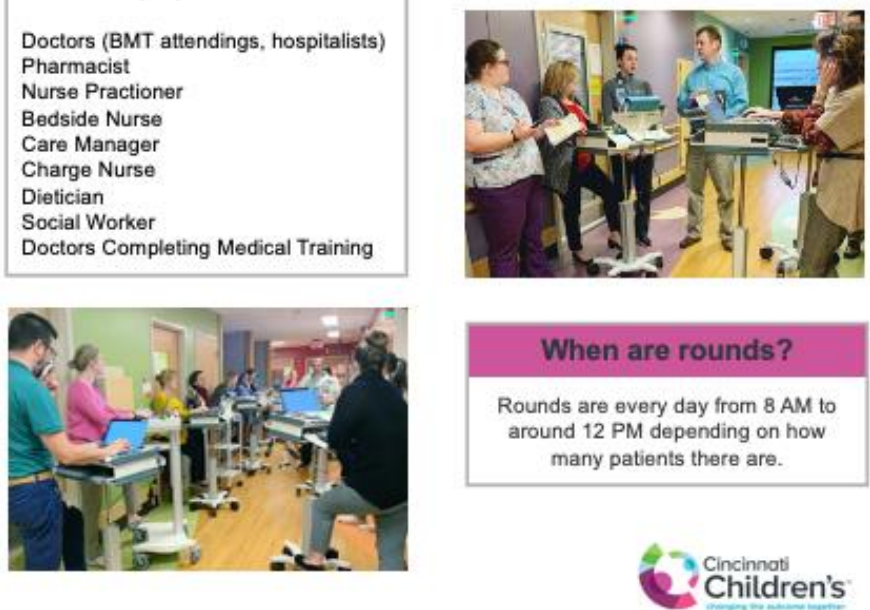

Fig. 3. Daily rounds educational poster 
We have also created preference magnets that parents could stick on the metal door frame of their room to indicate on a day to day basis that they do or do not want to be included in rounds today. This places more control in the hand of parents and is a straightforward way to communicate their preferences. This also helps the rest of the care team know if they should wait for a parent if they're not currently in the room or conduct rounds without disturbing them. (Fig. 4).

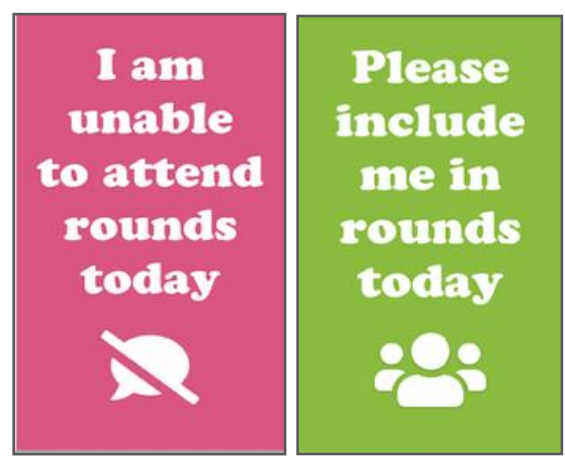

Fig. 4. Door magnets for daily rounds attendance

Family members and staff noted that many caregivers were called "mom" or "dad" instead of their actual names. To address this, our team redesigned the preference cards that hang outside a patient's room. We greatly enlarged the space for caregiver name, making it easier for someone to build rapport with the caregiver by greeting them by name. (Fig. 5).

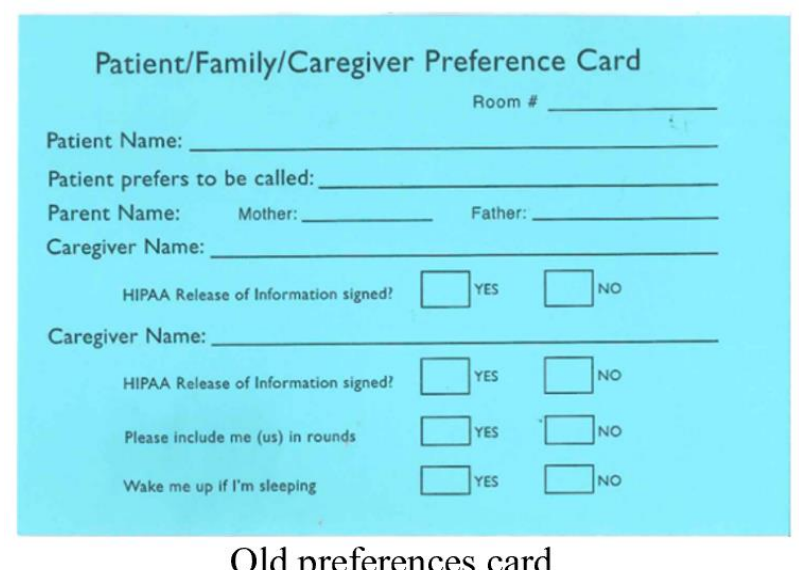

Old preferences card

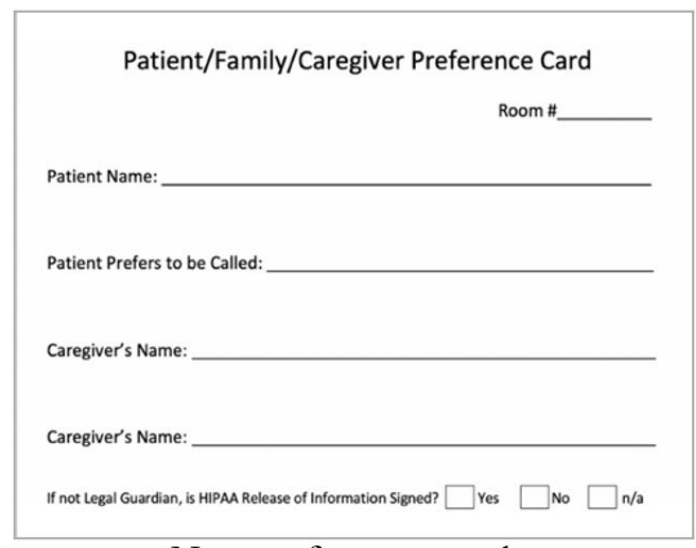

New preferences card

Fig. 5. Redesigned preference cards

Finally, we will be testing a system to have more frequent check-ins with our parents using various methods, including SMS messaging. Our goal is to provide a safe space for parents to inform us of communication breakdowns as they occur before they become problems and lead to significant frustration. 


\section{Conclusion}

The parents of the children we care for have critically important information that must be effectively shared to obtain optimal outcomes. Improving the system that supports effective communication is essential for delivering these outcomes, and we encourage other healthcare systems to join us on this journey.

\section{Author Statement}

The authors declare that they have no conflict of interest.

\section{Acknowledgements}

The authors thank the patients and families of Cincinnati Children's Hospital for their collaboration on this initiative.

\section{ORCID}

John F. Huber (iD https://orcid.org/0000-0001-6579-6714

Judith Dexheimer (iD https://orcid.org/0000-0002-4196-7846

Hannah Ingraham (iD https://orcid.org/0000-0002-6157-0598

Catherine Desmond (DiD https://orcid.org/0000-0002-1000-6620

Anna Klunk (iD https://orcid.org/0000-0002-4753-3459

Kati Kusnier (iD https://orcid.org/0000-0002-4899-0459

Dawn Nebrig (iD https://orcid.org/0000-0003-1188-1803

Laura Flesch (iD https://orcid.org/0000-0002-9260-4201

Annamarie Borich (DD https://orcid.org/0000-0003-0836-8101

Stella Davies (iD https://orcid.org/0000-0002-3137-6647

Christopher Dandoy (iD https://orcid.org/0000-0002-4001-9203

\section{References}

Arora, N. K., Street, R. L. Jr., Epstein, R. M., \& Butow, P. N. (2009). Facilitating patientcentered cancer communication: A road map. Patient Education and Counseling, 77(3), 319-321.

Aspen, P., Walcott, J., Bootman, J., \& Cronenwett, L. (2007). Preventing medication errors: Quality chasm series. Washington, DC. The National Academic Press.

Badia, P., Hickey, V., Flesch, L., Byerly, M., Sensibaugh, C., Potts, K., ... Beebe, D. (2019). Quality improvement initiative to reduce nighttime noise in a transplantation and cellular therapy unit. Biology of Blood and Marrow Transplantation, 25(9), 1844-1850.

Best, D., Osterkamp, E., Demmel, K., Kiniyalocts, S., Mock, S., Mulligan, K., ... Hawkins, D. (2016). Increasing activities of daily living is as easy as 1-2-3. Journal of 
Pediatric Oncology Nursing, 33(5), 345-352.

Coleman, K., Flesch, L., Petiniot, L., Pate, A., Lin, L., Crosby, L., ... Baker, R. B. (2018). Sleep disruption in caregivers of pediatric stem cell recipients. Pediatric Blood \& Cancer, 65(5): e26965.

Dandoy, C. E., Davies, S. M., Flesch, L., Hayward, M., Koons, C., Coleman, K., ... Powers, J. (2014). A team-based approach to reducing cardiac monitor alarms. Pediatrics, 134(6), e1686-e1694.

Desharnais, S., Carter, R. E., Hennessy, W., Kurent, J. E., \& Carter, C. (2007). Lack of concordance between physician and patient: Reports on end-of-life care discussions. Journal of Palliative Medicine, 10(3), 728-740.

Epstein, R. M., Duberstein, P. R., Fenton, J. J., Fiscella, K., Hoerger, M., Tancredi, D. J., ... Kaesberg, P. (2017). Effect of a patient-centered communication intervention on oncologist-patient communication, quality of life, and health care utilization in advanced cancer: The VOICE randomized clinical trial. JAMA Oncology, 3(1), 92100.

Epstein, R. M., Franks, P., Fiscella, K., Shields, C. G., Meldrum, S. C., Kravitz, R. L., \& Duberstein, P. R. (2005). Measuring patient-centered communication in patientphysician consultations: Theoretical and practical issues. Social Science \& Medicine, 61(7), 1516-1528.

Epstein, R. M., Franks, P., Shields, C. G., Meldrum, S. C., Miller, K. N., Campbell, T. L., \& Fiscella, K. (2005). Patient-centered communication and diagnostic testing. The Annals of Family Medicine, 3(5), 415-421.

Epstein, R. M., \& Street, R. L. (2007). Patient-centered communication in cancer care: Promoting healing and reducing suffering. National Cancer Institute, NIH Publication (No. 07-6225). Bethesda, MD.

Frosch, D. L., May, S. G., Rendle, K. A., Tietbohl, C., \& Elwyn, G. (2012). Authoritarian physicians and patients' fear of being labeled 'difficult' among key obstacles to shared decision making. Health Affairs, 31(5), 1030-1038.

Gratwohl, A., Baldomero, H., Aljurf, M., Pasquini, M. C., Bouzas, L. F., Yoshimi, A., ... Frauendorfer, K. (2010). Hematopoietic stem cell transplantation: A global perspective. JAMA, 303(16), 1617-1624.

Hashem, M. D., Nallagangula, A., Nalamalapu, S., Nunna, K., Nausran, U., Robinson, K. A., ... Eakin, M. N. (2016). Patient outcomes after critical illness: A systematic review of qualitative studies following hospital discharge. Critical Care, 20: 345.

Institute of Medicine (IOM). (2009). Assessing and improving value in cancer care: Workshop summary. Washington, DC: The National Academies Press

Kaziunas, E., Hanauer, D. A., Ackerman, M. S., \& Choi, S. W. (2016). Identifying unmet informational needs in the inpatient setting to increase patient and caregiver engagement in the context of pediatric hematopoietic stem cell transplantation. Journal of the American Medical Informatics Association, 23(1), 94-104.

Kerr, J., Engel, J., Schlesinger-Raab, A., Sauer, H., \& Holzel, D. (2003). Doctor-patient communication. Diseases of the Colon \& Rectum, 46(8), 1038-1046.

Khan, A., Furtak, S. L., Melvin, P., Rogers, J. E., Schuster, M. A., \& Landrigan, C. P. (2017). Parent-provider miscommunications in hospitalized children. Hospital Pediatrics, 7(9), 505-515.

King, A., \& Hoppe, R. B. (2013). "Best practice" for patient-centered communication: A narrative review. Journal of Graduate Medical Education, 5(3), 385-393.

Levine, W. C., \& Dunn, P. F. (2015). Optimizing operating room scheduling. Anesthesiology Clinics, 33(4), 697-711.

Llenore, E., \& Ogle, K. R. (1999). Nurse-patient communication in the intensive care unit: A review of the literature. Australian Critical Care, 12(4), 142-145. 
Majhail, N. S., Farnia, S. H., Carpenter, P. A., Champlin, R. E., Crawford, S., Marks, D. I., ... Savani, B. N. (2015). Indications for autologous and allogeneic hematopoietic cell transplantation: Guidelines from the American Society for Blood and Marrow Transplantation. Biology of Blood and Marrow Transplantation, 21(11), 1863-1869.

Makoul, G., \& Clayman, M. L. (2006). An integrative model of shared decision making in medical encounters. Patient Education and Counseling, 60(3), 301-312.

Muething, S. E., Kotagal, U. R., Schoettker, P. J., del Rey, J. G., \& DeWitt, T. G. (2007). Family-centered bedside rounds: A new approach to patient care and teaching. Pediatrics, 119(4), 829-832.

National Priorities Partnership. (2008). National priorities and goals: Aligning our efforts to transform America's healthcare. Washington, DC: National Quality Forum.

Passweg, J. R., Baldomero, H., Peters, C., Gaspar, H. B., Cesaro, S., Dreger, P., ... Halter, J. (2014). Hematopoietic SCT in Europe: Data and trends in 2012 with special consideration of pediatric transplantation. Bone Marrow Transplantation, 49(6), 744750 .

Rosenberg, R. E., Rosenfeld, P., Williams, E., Silber, B., Schlucter, J., Deng, S., ... Sullivan-Bolyai, S. (2016). Parents' perspectives on "keeping their children safe" in the hospital. Journal of Nursing Care Quality, 31(4), 318-326.

Sobo, E. J., Seid, M., \& Gelhard, L. R. (2006). Parent-identified barriers to pediatric health care: A process-oriented model. Health Services Research, 41(1), 148-172.

Sutcliffe, K. M., Lewton, E., \& Rosenthal, M. M. (2004). Communication failures: An insidious contributor to medical mishaps. Academic Medicine, 79(2), 186-194.

Treiman, K., McCormack, L., Wagner, L., Roach, N., Moultrie, R., Sanoff, H., ... Reeve, B. B. (2018). Factors affecting the communication experiences of newly diagnosed colorectal cancer patients. Patient Education and Counseling, 101(9), 1585-1593.

Weeks, J. C., Catalano, P. J., Cronin, A., Finkelman, M. D., Mack, J. W., Keating, N. L., \& Schrag, D. (2012). Patients' expectations about effects of chemotherapy for advanced cancer. The New England Journal of Medicine, 367(17), 1616-1625. 